\title{
Interactions between sediments and water: perspectives on the 12th International Association for Sediment Water Science Symposium
}

\author{
Geraldene Wharton • Brian Kronvang • Nives Ogrinc • \\ William H. Blake
}

Received: 8 September 2012 / Accepted: 12 September 2012 /Published online: 25 September 2012

(C) Springer-Verlag Berlin Heidelberg 2012

\section{Introduction}

The International Association for Sediment Water Science (IASWS) is an inter-disciplinary organisation whose mandate is "to promote, encourage and recognise excellence in scientific research related to sediments and their interactions with water and biota in fluvial, lacustrine and marine systems and with particular reference to problems of environmental concern" (www.iasws.org). IASWS grew out of a meeting of an international group of interdisciplinary aquatic scientists in Amsterdam in 1976, and at a second meeting in Kingston, Canada (1981), the organisation was officially formed. Since then, symposia have been held every 3 years in: Geneva, Switzerland (1984); Melbourne, Australia (1987); Uppsala, Sweden (1990); Santa Barbara, USA

G. Wharton $(\bowtie)$

School of Geography, Queen Mary, University of London, Mile End Road,

London E1 4NS, UK

e-mail: g.wharton@qmul.ac.uk

\section{B. Kronvang}

Department of Bioscience, Faculty of Science and Technology,

Aarhus University,

Vejlsøvej 25,

8600 Silkeborg, Denmark

\section{N. Ogrinc}

Department of Environmental Sciences, Jožef Stefan Institute, Jamova 39,

1000 Ljubljana, Slovenia

\section{W. H. Blake}

School of Geography, Earth and Environmental Sciences,

Plymouth University,

Plymouth,

Devon PL4 8AA, UK
(1993); Baveno, Italy (1996); Beijing, China (1999); Banff, Canada (2002); Lake Bled, Slovenia (2005); Esperance, Australia (2008); and Dartington, England (2011; see Petticrew (2009) for a detailed review of the history of IASWS). The 13th Symposium is planned for Rhodes University, Grahamtown, South Africa in 2014. Since 1976, over 1,000 oral presentations have been given at these symposia with a large proportion of these papers published as conference books and/or special issues of scientific journals (Petticrew 2009). This Preface to the Special Issue of the 12th IASWS Symposium first reflects on the main topics presented in Dartington in 2011 and then considers the papers published in the Journal of Soils and Sediments in greater detail, placing them in the context of past IASWS themes and emerging debates in sedimentwater science.

\section{The 2011 Dartington symposium}

The 72 oral papers presented at the 2011 Symposium were grouped into 20 sessions with six main themes:

1. Biota as ecosystem engineers of biogeochemical processes (one session, four papers)

2. Dynamics of fine cohesive sediments (two sessions, six papers)

3. Characterisation of sediment-bound nutrients and contaminants (two sessions, six papers);

4. Fluxes and storage of sediments, contaminants and nutrients in natural and disturbed systems (10 sessions, 39 papers) and modelling of these fluxes (one session, four papers)

5. Management of water, sediments, nutrients and contaminants (one session, four papers) and managing 
sediment quality and remediation of sediments (one session, three papers)

6. Use of tracer technologies in sediment-water science (two sessions, six papers)

Plenary sessions were planned to link as closely as possible to the six key session themes and were given by: David Paterson, University of St Andrews, "Mud, microbes and man: the biology of sediment dynamics"; Angela Gurnell, Queen Mary, University of London, "Plants as river ecosystem engineers"; Carl Amos, University of Southampton, "Temperature trends in coastal waters-possible impacts on sedimentation, with reference to Venice lagoon"; Oscar Schoumans, Wageningen University, "Interaction between land, sediments and surface water quality in different aquatic systems"; Sue White, Cranfield University, "Frameworks for sediment management"; and Des Walling, University of Exeter, "The use of fallout radionuclides in the study of soil erosion and catchment sediment budgets: recent progress and future prospects".

Research on sediment-associated nutrients and contaminants has been the dominant recurring theme over the past 30 years (Petticrew et al. 2006) and the 2011 Symposium was no exception with over $50 \%$ of all papers focusing on sediment, nutrient and contaminant fluxes. Research on sediment dynamics has also been well represented at all IASWS Symposia and two sessions (six papers) were devoted to this topic at Dartington. Developments in the application of sediment tracing technologies fit well within this framework. Examples presented at Dartington illustrated how tracers can inform management decisions but also highlighted new opportunities and research needs against increasingly complex research and management questions. The final day of the conference had a clear management focus, with: some papers on international standards and monitoring of sediment quality, which is a pressing issue in the context of implementing legislation such as the EU Water Framework Directive; a plenary paper that presented a modelling framework for catchment-scale sediment management; and an ADAS-sponsored session looking at catchment-scale research and management policy. These sessions began to highlight the need for sediment scientists to engage with policy makers and consider social and economic issues to ensure that the best science informs developments and is adopted by environmental managers (see also Petticrew et al. 2006).

The 29 symposium posters were also dominated by research on sediment, nutrient and contaminant fluxes (12 papers). Seven posters considered the role of biota in sediment-water interactions; there were four managementfocused posters; two on sediment dynamics; but only one on the characterisation of sediments. There were no posters on the use of tracers in sediment research but there were three methodological/technological posters. No posters considered climate change impacts and only one poster had a restoration/remediation focus.

\section{IASWS and the Journal of Soils and Sediments}

The year 2010 was the 10th Anniversary of the Journal of Soils and Sediments (JSS) and there was some subsequent restructuring of the journal to reflect recent developments and directions (Xu and Owens 2011). The JSS "sediments" part of the journal now comprises five sections covering a wide breadth of sediment research: (1) sediment quality and impact assessment; (2) physical and biogeochemical processes; (3) hillslope and river basin sediment dynamics; (4) sediment-ecology interactions; and (5) sediment management (Owens and Xu 2011; Xu and Owens 2011). With few dedicated sediments journals in the past, research on sediments has tended to be published in the geomorphology, hydrology and environmental science literature. Furthermore, sediment research has become more collaborative and interdisciplinary in recent years and the restructured JSS offers a perfect platform for the publication of inter-disciplinary sediment science conducted at all scales along the catchment to coast continuum. These five "sediments" sections of JSS also fit closely with the mandate of IASWS and thus JSS offers a natural home for the publication of papers from IASWS Symposia.

Importantly, at the 12th IASWS Symposium, a formal agreement was reached between IASWS and JSS for the publication of papers from IASWS symposia. This is an exciting development for the organisation given the close agreement between the association's mandate and the JSS sediments sections (Owens and $\mathrm{Xu}$ 2011), and ensures a high quality outlet for future IASWS publications. The 16 papers published in this first JSS/IASWS Special Issue, and the two further papers from the symposium published in other issues of volume 12 (Grabowski et al. 2012; Owens et al. 2012), provide an example of the current research foci of this international and inter-disciplinary research community and, when viewed in the context of past IASWS publications, valuable insight is gained into the changing research directions of sediment-water science. Several additional manuscripts based on presentations given at the 12th IASWS Symposium are being reviewed and likely to be published in JSS in 2013.

\section{Emerging themes from the JSS special issue publications}

The analysis of Petticrew (2009) on key themes and trends in IASWS publications over the 30-year period 1976-2006 
provides an important historical framework for considering the papers published from the 2011 Symposium. Four key themes were identified over the 30-year period (sediment dynamics; contaminant accumulation, distribution and remediation; bioavailability and effects of contaminants on biota; and material cycling at the sediment-water interface) displayed as a Venn-like diagram to stress that the themes are not independent (see Petticrew 2009, Fig. 2). Subthemes of "land use impacts" and "sediment management and risk analysis" were also noted and papers were further characterised by the scale of study (e.g. micro, reach, catchment), the environment studied (fluvial, lacustrine, marine) and by the methodological approach (field, laboratory or modelling). Thus, the 16 papers selected to be published in this Special Issue, and two further papers from the symposium published in volume 12 (Grabowski et al. 2012; Owens et al. 2012) were analysed for content, searching for these key descriptors to provide historical continuity, although the biological theme was widened to include any paper that reported on the role of biota in sediment-water interactions.

Consistent with past IASWS trends and also the large number of oral presentations at the Dartington Symposium, the highest number of published papers (nine) considered nutrients and contaminants in sediments with a large proportion focusing on fluxes (Arai and Fukushima 2012; Campanha et al. 2012; Inoue and Nakamura 2012; Kadiri et al. 2012; Kleeberg et al. 2012; Koron and Faganeli 2012; Koschorreck and Wendt-Potthoff 2012); one paper considering heavy metal concentrations in sediments and aquatic plants (Sun et al. 2012); and one reporting on the numerical modelling of PAHs in aquatic bed sediments (Go and Stegemann 2012). Several of these nutrient and contaminant papers also link to other themes. The paper by Sun et al. (2012) is concerned with the impact of heavy metals on plants and the papers by Arai and Fukushima (2012) and Koschorreck and Wendt-Potthoff (2012) both have elements that address the role of biota in sediment-water interactions. Indeed, the role of biota is well represented with six published papers (Arai and Fukushima 2012; Grabowski et al. 2012; Janson et al. 2012; Koschorreck and Wendt-Potthoff 2012; Škrinjar et al. 2012; Sun et al. 2012). There is also overlap between the nutrients and contaminants and material cycling themes since four of the seven material cycling papers address fluxes of nutrients and/or contaminants at the sediment-water interface (Campanha et al. 2012; Inoue and Nakamura 2012; Kadiri et al. 2012; Koron and Faganeli 2012).

The published papers are spread across a wide range of aquatic environments and interestingly are dominated by research conducted at relatively large scales with in situ field measurements or sampling of sediments providing the spatial coverage across rivers reaches (Grabowski et al.
2012; Sun et al. 2012) and different rivers (Campanha et al. 2012), catchments (Grangeon et al. 2012; Owens et al. 2012; Palumbo-Roe et al. 2012), estuaries and inter-tidal areas (Denis et al. 2012; Go and Stegemann 2012; Janson et al. 2012), lakes (Arai and Fukushima 2012; Fukushima et al. 2012; Kleeberg et al. 2012; Koschorreck and WendtPotthoff 2012) and marine environments (Koron and Faganeli 2012; Morata et al. 2012; Škrinjar et al. 2012). Petticrew (2009) noted the trend for greater reporting of catchment-scale projects in more recent years and linked this trend to the increasing availability of Geographical Information Systems and electronic databases, and with more catchment-based policy and management initiatives now emerging this trend seems likely to continue.

In terms of the methodological approach, 14 out of the 18 papers report field-based measurements or in situ experiments. This continues the trend identified by the content analysis of Petticrew (2009) of all 524 IASWS published papers from 1976 to 2006 , which revealed $58-81 \%$ of research to be field based. In contrast, papers reporting modelling and laboratory-based research have been fewer in number over the decades and this Special Issue follows this trend. Only one paper is entirely modelling focused (Go and Stegemann 2012), as previously mentioned, although Inoue and Nakamura (2012) combined laboratory flume experiments with a numerical modelling approach; and a laboratory experimental approach was also employed by Kadiri et al. (2012), using microcosms and batch sorption experiments to simulate contaminant releases from dredged sediments.

\section{Conclusions and future directions in sediment-water science}

The 2011 IASWS Symposium brought together scientists from a large number of disciplinary backgrounds and from 24 countries. Changing research interests in sediment-water science and methodological and technological advancements in the study of sediment-water environments are evident from the IASWS publications over the past three decades and have been accommodated by these flexible symposia. This ability to promote newly emerging research ensures that although there are many long-standing attendees of IASWS Symposia who provide an invaluable continuity to the organisation, there are also many new participants every 3 years attracted by the symposium themes. The result is a dynamic community with new expertise and ideas being gained at each symposium. One way in which this is facilitated is through the active encouragement of student participation. In Dartington, there were 22 student participants and two received bursaries from IASWS to attend the symposium. 
Research on fluxes of sediments, contaminants and nutrients continues to dominate IASWS presentations and publications. However, one of the pressing challenges facing sediment-water scientists is to advance understanding of the combined effect of a range of stressors since biotic communities in the aquatic environment are shaped not by individual contaminants but by numerous environmental variables that act at multiple spatial and temporal scales (e.g. Friberg 2010). Since the start of industrialisation, aquatic ecosystems have received toxic compounds (e.g. metals, PAHs, PCBs and pesticides) from point sources (such as mines and industrial plants) and diffuse agricultural pollution sources (Stanners and Bourdeau 1995). These compounds are still a major problem in many countries worldwide but water bodies are also heavily impacted by eutrophication (not least due to farming), organic pollution, flow regulations, hydro-morphological degradation, pesticides and climate change; the latter also influencing the loading of dissolved organic carbon and sediments. While research has been conducted on the ecological effect of individual stressors, little is known about the combined effects and how to mitigate such effects in water and sediment. With an inter-disciplinary membership and a mandate to advance research related to sediments and their interactions with water and biota in fluvial, lacustrine and marine systems and with particular reference to problems of environmental concern (www.iasws.org) this is a challenge that IASWS members can begin to address in the coming years. Perhaps we will receive papers examining multiple stressors at the next symposium in South Africa, planned for September 2014 (see www.iasws.org for further details). We certainly look forward to welcoming new participants as well as IASWS regulars to the next symposium.

Acknowledgments The authors would like to acknowledge the support (financially and in-kind) from: the International Association for Sediment Water Science (IASWS); the School of Geography, Queen Mary, University of London, UK; the School of Geography, Earth and Environmental Sciences, Plymouth University, UK; the Department of Bioscience, Aarhus University, Denmark; and the Department of Environmental Science, Jožef Stefan Institute, Slovenia. The IASWS Scientific Committee are grateful to the following organisations for their sponsorship of the 12th IASWS Symposium: ADAS; In Situ Inc.; OSIL Environmental instruments and systems; The UK River Restoration Centre; RS Hydro; Plymouth University Marine Institute; Plymouth University Consolidated Radioisotope Facility; Valeport Oceanographic, Hydrographic and Hydrometric Instrumentation; Westcountry Rivers Trust; and YSI Hydro data. This Special Issue was sponsored by ADAS.

\section{References}

Arai H, Fukushima T (2012) Silicon budget of eutrophic Lake Kasumigaura, Japan. J Soils Sediments (this issue)

Campanha MB, Moreira AB, Bisinoti MC (2012) Metal fluxes at the sediment-water interface in rivers from the Turvo/Grande drainage basin, Sao Paulo State, Brazil. J Soils Sediments (this issue)
Denis L, Gevaert F, Spilmont N (2012) Microphytobenthic production estimated by in situ oxygen microprofiling: short-term dynamics and carbon budget implications. J Soils Sediments (this issue)

Friberg N (2010) Pressure-response relationships in stream ecology: introduction and synthesis. Freshw Biol 55:1367-1381

Fukushima T, Watanabe S, Kamiya K, Ozaki N (2012) Vertical distributions of PAHs in the sediments of four lakes in Japan. J Soils Sediments (this issue)

Go J, Stegemann JA (2012) Modelling post-depositional transport of PAHs in aquatic bed sediments using CoReTrans. J Soils Sediments (this issue)

Grabowski RC, Wharton G, Davies GR, Droppo IG (2012) Spatial and temporal variations in the erosion threshold of fine river bed sediments. J Soils Sediments 12:1174-1188

Grangeon T, Legout C, Esteves M, Gratiot N, Navratil O (2012) Variability of the particle size of suspended sediment during highly concentrated flood events in a small mountainous catchment. J Soils Sediments (this issue)

Inoue T, Nakamura Y (2012) Response of benthic soluble reactive phosphorus transfer rates to step changes in flow velocity. J Soils Sediments (this issue)

Janson A, Denis L, Rauch M, Desroy N (2012) Macrobenthic biodiversity and oxygen uptake in estuarine systems: the example of the Seine estuary. J Soils Sediments (this issue)

Kadiri M, Spencer KL, Heppell CM (2012) Potential contaminant release from agricultural soil and dredged sediment following managed realignment. J Soils Sediments (this issue)

Kleeberg A, Kohler A, Hupfer M (2012) How effectively does a single or continuous iron supply affect the phosphorus budget of aerated lakes? J Soils Sediments (this issue)

Koron N, Faganeli J (2012) Benthic fluxes of mercury during redox changes in pristine coastal marine sediments from the Gulf of Trieste (northern Adriatic Sea). J Soils Sediments (this issue)

Koschorreck M, Wendt-Potthoff K (2012) A sediment exchange experiment to assess the limiting factors of microbial sulphate reduction in acidic mine pit lakes. J Soils Sediments (this issue)

Morata T, Sospedra J, Falco S, Rodilla M (2012) Exchange of nutrients and oxygen across the sediment-water interface below a Sparus aurata marine fish farm in the north-western Mediterranean Sea. J Soils Sediments (this issue)

Owens PN, Xu ZH (2011) Recent advances and future directions in soils and sediments research. J Soils Sediments 11:875-888

Owens PN, Giles TR, Blake WH, Williams ND (2012) Determining the effects of wildfire on sediment sources using ${ }^{137} \mathrm{Cs}$ and unsupported ${ }^{210} \mathrm{~Pb}$ : the role of landscape disturbances and driving forces. J Soils Sediments 12:982-994

Palumbo-Roe B, Wragg J, Banks VJ (2012) Lead mobilisation in the hyporheic zone and river bank sediments of a contaminated stream: contribution to diffuse pollution. J Soils Sediments (this issue)

Petticrew EL (2009) Thirty years of sediment-water science: history, trend and future directions. Mar Freshw Res 60:611-618

Petticrew EL, Droppo IG, Ogrinc N, Kronvang B, Faganeli J (2006) Interactions between sediment and water: perspectives on the 10th International Association for Sediment Water Science Symposium. Water Air Soil Pollut Focus 6:356-369

Škrinjar PL, Faganeli J, Ogrinc N (2012) The role of stromatolites in explaining patterns of carbon, nitrogen, phosphorus and silicon in the Sečovlje saltern evaporation ponds (northern Adriatic Sea). J Soils Sediments (this issue)

Stanners D, Bourdeau P (eds) (1995) Europe's environment. The Dobris assessment. European Environmental Agency, Copenhagen

Sun W, Sang L, Jiang B (2012) Trace metals in sediments and aquatic plants from the Xiangijang River, China. J Soils Sediments (this issue)

Xu ZH, Owens PN (2011) Developments and directions of the Journal of Soils and Sediments: 2011 and beyond. J Soils Sediments $11: 1-2$ 